\title{
INOVAÇÃO E TOMADA DE DECISÃO NO PROCESSO DE LOGÍSTICA REVERSA: UMA ANÁLISE BIBLIOMÉTRICA
}

\section{INNOVATION AND DECISION-MAKING PROCESS IN REVERSE LOGISTICS: A BIBLIOMETRIC ANALYSIS}

\author{
Fernando Antônio Guimarães Tenório* E-mail: ftenorio 561@hotmail.com \\ Débora Eleonora Pereira da Silva*E-mail: dsilva.ufs@gmail.com \\ Antonio Luiz Rocha Dacorso* E-mail: antoniodacorso@gmail.com \\ * Universidade Federal de Sergipe, São Cristóvão, SE
}

Resumo: Este trabalho buscou fazer uma análise bibliométrica acerca de estudos empíricos cujo foco seja o processo da logística reversa. Foram levantados trabalhos publicados em dois grandes eventos de administração e um de engenharia da produção, durante os anos de 2007 a 2012. Para realizar a análise foram adotados como pressupostos os conceitos de inovação e processo decisório. Foram analisados 43 artigos e constatou-se que, na maioria dos casos, as organizações decidem implantar a logística reversa como maneira de solucionar problemas relacionados a leis e normas ambientais e, após sua implantação, o processo decisório relacionado à rede de empresas que executam a logística reversa continua sendo restrito à empresa adotante, tornando-se assim, um processo decisório centralizado. Também ficou constatado que a logística reversa representa, na maioria dos casos, uma inovação na cadeia de suprimentos, pois proporciona uma nova maneira de gerenciar e operacionalizar o retorno e reaproveitamento de produtos e resíduos, gerando vantagens competitivas na forma de aumento do lucro líquido e melhor imagem da organização perante seus parceiros e clientes.

Palavras-chave: Logística reversa. Inovação. Tomada de decisão. Serviço. Processo.

Abstract: This work aimed to make a bibliometric analysis on empirical studies that focus on the reverse logistics process. Papers published in two major events of management and a production engineering were collected during the years 2007-2012. To perform the analysis assumptions were adopted as the concepts of innovation and decision-making. 43 articles were analyzed and it was found that, in most cases, organizations choose to deploy reverse logistics as a means to solving problems related to environmental laws and regulations and after its implementation, the decisionmaking process related to the network of companies that perform reverse logistics remains restricted to the adopter company, thus becoming a centralized decision-making process. It was also found that reverse logistics is, in most cases, an innovation in the supply chain, it provides a new way to manage and operate the return and recycling of waste products and generating competitive advantages in the form of increased net income and better picture of the organization to its partners and customers.

Keywords: Reverse Logistics. Innovation. Decision making. Service. Process.

\section{INTRODUÇÃO}

No final do século XX, mais precisamente na década de 1970, a preocupação com o meio ambiente começou a disseminar na sociedade de forma geral (WHITE,

Revista Produção Online, Florianópolis, SC, v.14, n. 2, p. 593-616, abr./jun. 2014. 
2013; BARBIERI, 2011), devido, entre outros fatores, à mudança cultural pela qual a civilização passava naquele momento e por eventos como a crise do petróleo, que afetou o modelo de produção capitalista vigente (CAMPOS; MELO, 2008).

Nesse período e nas décadas posteriores ocorreram diversas reuniões entre os governos de diversos países, tais como a conferência de Estocolmo, em 1972, a ECO-92, realizada em 1992 e, mais recentemente, a Rio +20, em 2012, com o intuito de prover ações e acordos na tentativa de reduzir o impacto que o modelo econômico causa ao meio ambiente, fazendo com que o termo desenvolvimento sustentável, ou de modo mais simples, sustentabilidade, torna-se comum em todo o mundo (BARBOSA; OLIVEIRA, 2012; PRZYCHODZEN; PRZYCHODZEN, 2013).

Segundo White (2013), a sustentabilidade possui mais de duzentas diferentes definições, tendo em comum o fato de agregarem questões ambientais, tais como a preservação de biomas e pureza do ar e água; sociais, como garantir a dignidade e saúde e; econômicas, garantindo o retorno financeiro das empresas em relação a realização de suas atividades (MACAGNO, 2013).

De forma holística, pode-se definir sustentabilidade como um modelo de desenvolvimento que atenda às gerações atuais sem comprometer o desenvolvimento das gerações futuras, ou seja, modos de produção de bens e serviços economicamente viáveis, com responsabilidade social e sem prejudicar o meio ambiente (CMMAD, 1988; MUNASINGHE, 2007).

As pressões governamentais, oriundas de leis ambientais mais severas, a crescente preocupação da sociedade com o meio ambiente, a escassez de recursos naturais, o aumento da poluição e o fortalecimento de organizações não governamentais de defesa ao meio ambiente (GONÇALVES-DIAS; TEODOSIO, 2011; SELLITO, et al., 2013) vêm obrigando as empresas a gerarem produtos e serviços sustentáveis (MACAGNO, 2013). Ademais, a redução de custos obtida com o uso de matéria-prima secundária e uma imagem, perante seus clientes, de empresa amiga do ambiente pode proporcionar vantagens competitivas, que de acordo com pesquisa realizada com 93\% dos CEOs mundiais, são as condições essenciais para o sucesso das empresas atualmente (PRZYCHODZEN; PRZYCHODZEN, 2013). 
Dessa forma, diversas organizações já consideram a sustentabilidade como um dos principais fatores a serem discutidos em suas estratégias de negócio (PRZYCHODZEN; PRZYCHODZEN, 2013) e procuram implantar instrumentos de gestão ambiental, tais como a logística reversa, definida como uma inovação em serviço que complementa a cadeia de distribuição. Com esta logística é possível o controle e a operacionalização, de forma eficiente, do retorno ao ciclo produtivo dos produtos que perderam sua utilidade, o que garante um impacto menor do descarte de produtos no ambiente e um modelo de produção que utiliza, em menor escala, matérias-primas oriundas da natureza (MILLER; SARDER, 2012).

Contudo, a tomada de decisão em implantar instrumentos de gestão ambiental, tais como a logística reversa, deve ser analisada com cautela por parte dos gerentes e demais partes interessadas, considerando todo o contexto que envolve a implantação de tais processos e o que eles visam solucionar (CINTRA et al., 2013; NOORAIE, 2013)

Com os preâmbulos citados, foi desenvolvido este estudo que tem como objetivo realizar uma análise bibliométrica por meio de artigos empíricos publicados entre os anos de 2007 e 2012 que apresentem estudos de caso sobre o processo de logística reversa. Foram considerados os artigos provenientes de dois eventos no campo da administração, o ENAMPAD e o SIMPOI, e um da área de engenharia da produção, o ENEGEP. Estes artigos foram analisados com o propósito de esclarecer: (a) quais são as vantagens competitivas relacionadas ao uso desse processo, que pode ser considerado um serviço inovador; (b) por que as empresas tomam a decisão em adotar a logística reversa e; (c) como é o processo decisório na cadeia reversa, já que a logística reversa possui diversas etapas que são, muitas vezes, compostas por diferentes empresas, formando uma rede interorganizacional.

\section{REFERENCIAL TEÓRICO}

\subsection{Inovação em Serviços}

A inovação, para o senso comum, está relacionada a algo novo, que pode ser um produto, processo ou serviço, que tem sua origem na indústria sendo dela dependente (MOREIRA; VARGAS, 2012). Nas organizações, a inovação está Revista Produção Online, Florianópolis, SC, v.14, n. 2, p. 593-616, abr./jun. 2014. 
relacionada diretamente com a manutenção de vantagens competitivas, que buscam atender as exigências dos consumidores por novos e melhores produtos, na intenção de manter uma posição de liderança frente à concorrência (ARAUJO; ZILBER, 2013; MOREIRA; VARGAS, 2012; VERMA; RAJAGOPAL, 2013).

No âmbito acadêmico, pesquisas relacionadas à inovação tiveram início no fim da década de 1930 por meio do trabalho de Schumpeter (1939), que propôs o estudo da inovação subdividido em cinco áreas, sendo elas: a inovação em produto, em processo, mercado, entrada e organizacional. Posteriormente, na década de 1960, Rogers (1962) amplia o trabalho de Schumpeter (1939), ao dividir as inovações em radicais, ou seja, algo totalmente novo para a sociedade de modo geral e incrementais, sendo essa a melhoria em um produto ou serviço.

Mesmo possuindo mais de 60 anos de estudos acadêmicos, não existe, até os dias atuais, um conceito universal sobre o que vem a ser inovação (RESENDE JUNIOR; GUIMARÃES, 2012), sendo, segundo Wu, Ma e Yang (2013), um constructo formado por diferentes definições e tipos.

$\mathrm{Na}$ literatura internacional são encontradas diversas definições para inovação. Autores clássicos, tais como Shumpeter (1982), define inovação como novas combinações que levam a novos produtos ou serviços que gerem resultados econômicos. Já autores como Smith (2008) e Fiates e Fiates (2008), adotam um conceito mais simples de inovação, podendo ser definido como um novo produto, serviço ou processo que gerem retornos econômicos as empresas que os adotam

De maneira mais completa que os autores supracitados, Lounsbury e Crumley (2007), veem a inovação como um processo composto de várias fases que tem como ponto de partida um problema específico, que pode ser solucionado por meio de uma prática inovadora para uma empresa em específico, que deve ser aceita pelos diversos agentes envolvidos no problema.

Corroborando Lounsbury e Crumley (2007), McMurray et al., (2013) afirmam que inovação é um processo composto por vários estágios que envolve lideres, empregados e componentes organizacionais tais como cultura e clima, no sentido de criar novas ideias e colocá-las em prática, podendo essas ideias, segundo Wu, Ma e Yang (2013), ocorrerem em relação a novos produtos, serviços, processos, posição, estratégia e governança.

Revista Produção Online, Florianópolis, SC, v.14, n. 2, p. 593-616, abr./jun. 2014. 
No que concerne à inovação voltada para serviços, essa ganhou espaço na academia a partir da década de 1970, quando modelos de produção flexíveis, tais como o Toyotismo e Volvismo passaram a substituir o modelo de produção Fordista, fazendo com que os serviços se tornassem essenciais para garantir a flexibilidade da produção, além de agilizar e incrementar a circulação de mercadorias (MOREIRA; VARGAS, 2012).

Autores clássicos como Barras (1986) e Davenport (1992) afirmam que a inovação em serviços é responsável por criar ou modificar a forma como um serviço é realizado. Em complemento aos referidos autores, Resende Junior e Guimarães (2012) afirmam que a inovação em serviços consiste em um processo de busca, descoberta, experimentação, desenvolvimento, imitação e posterior adoção de novos serviços, divididos em três abordagens (MOREIRA; VARGAS, 2012):

- Tecnicista: Adoção de novos serviços oriundos da implantação de Tecnologias da Informação e Comunicação;

- Orientada a serviços: Introdução de um novo serviço cujo foco é a interação entre elos de uma cadeia, tais como produtor/cliente e produtor/fornecedor;

- Integradora: concilia a inovação de produtos e serviços em uma só teoria genérica e mantém as características inerentes de cada uma. A abordagem integradora justifica-se pelo fato dos serviços também gerarem produtos provenientes da combinação entre a forma como o serviço é utilizado (competência dos clientes), a forma como ele é disponibilizado (competência do prestador) e das características técnicas materiais e imateriais.

Vale destacar que, tomando como base a abordagem orientada a serviços, Verma e Rajaporal (2013) afirmam que mudanças na forma como uma cadeia de suprimentos é operada e gerenciada pode ser considerada uma inovação em serviços, que impacta em todos os atores envolvidos, desde o consumidor até o fornecedor da matéria-prima (RESENDE JUNIOR; GUIMARÃES, 2012)

Assim, pode-se considerar a logística reversa como um novo serviço que integra a cadeia de suprimentos tradicional, ao gerenciar e operar o retorno de produtos de pós-consumo ou pós-venda, contribuindo para um modelo de produção 
mais sustentável que permite às empresas tomarem a decisão de adotá-la na busca de vantagens competitivas, tais como redução de custos e imagem diferenciada da organização perante seus parceiros e clientes, ou para solucionar problemas relacionados a leis ambientais.

\subsection{Logística Reversa}

A logística é uma das atividades mais antigas da humanidade, visto seu principal objetivo: disponibilizar bens produzidos por uma sociedade nos locais, no tempo, na quantidade e na qualidade exigidas por seus consumidores (LEITE, 2009). Contudo, o termo logística só passou a ser utilizado no século XIX, primeiramente no meio militar, como uma estratégia relacionada às formas de transporte de tropas e suprimentos nos períodos de guerra (FERREIRA FILHO et al., 2011).

Nas organizações o uso da logística é recente, tendo início a partir da segunda metade do século $X X$ quando modelos de produção enxuta começaram a se disseminar nas empresas (LEITE, 2012), fazendo com que a logística fosse usada como forma de gerar vantagens competitivas relacionadas à redução de custos e ganhos de mercado, por meio de formas eficientes para a produção e distribuição de produtos, dando origem a chamada logística empresarial (CHAN; ZHANG, 2011).

A logística empresarial é um processo que tem por objetivo gerenciar, organizar e coordenar a aquisição, movimentação e armazenagem de matériasprimas, peças e serviços, composta pela: (a) logística de suprimento, encarregada de suprir a empresa de matéria-prima necessária a produção; (b) logística de produção, responsável por planejar e operar o fluxo interno de manufatura; (c) logística de distribuição, cuja função é a distribuição do produto acabado a consumidores e varejistas e, mais recentemente, a logística reversa, que reinsere produtos que perderam sua utilidade ao ciclo produtivo e de negócios por meio dos canais de distribuição reversos (PORTUGAL et al., 2012).

Para Faria e Pereira (2012), a logística reversa foi incluída no processo de logística empresarial como uma forma de minimizar o uso de matéria-prima oriunda

Revista Produção Online, Florianópolis, SC, v.14, n. 2, p. 593-616, abr./jun. 2014. 
da natureza que tem o custo elevado, devido sua escassez, e encarece o processo produtivo.

Em complemento a Faria e Pereira (2012), Portugal et al. (2012) afirmam que além da questão dos custos, fatores como a crescente preocupação ambiental, por parte da sociedade, fez com que a logística reversa fosse adotada como uma alternativa de agregação de valor ecológico e legal, gerando vantagens competitivas relacionadas à redução de custos e melhoria da imagem das empresas perante parceiros, clientes e poder público.

No âmbito acadêmico, estudos relacionados à logística reversa tiveram início na década de 1970, geralmente associados à reciclagem de materiais (LAGARINHOS; TENORIO, 2013). Ademais, Sheu e Talley (2011) entendem que o interesse acadêmico por estudos sobre a logística reversa possui relação direta com o conceito de responsabilidade estendida do produtor, em que indústrias devem formular estratégias para realizar o retorno e destinação final ambientalmente adequada de seus produtos, com vistas a reduzir a agressão ao meio ambiente.

Apesar de ter seu início nos anos 1970, o tema logística reversa só passou a ser considerado campo de estudos a partir dos anos 1990 (RUBIO; CHAMORRO; MIRANDA, 2008), o que fez com que sejam escassos os estudos relacionados ao tema, principalmente no Brasil (HERNANDEZ; MARINS; CASTRO, 2012), não possuindo até os dias atuais uma definição predominantemente aceita (SELLITO, et al. 2013).

Assim, são encontrados na literatura, diversos conceitos e constructos sobre o termo logística reversa, alguns inclusive referenciam o termo como cadeia de suprimentos reversa, tal qual o trabalho de Zucatto, Welle e Silva (2013) ao definir a logística reversa como uma cadeia de suprimentos responsável pelo fluxo reverso de bens e produtos que perderam sua utilidade ao ciclo produtivo. De forma semelhante Pochampally, Nukala e Gupta (2009) definem a cadeia reversa como um conjunto de atividades necessárias à coleta e reaproveitamento ou disposição final adequada de produtos usados.

Já Flygansvaer, Gadde e Haughland (2008) denominam logística reversa como um sistema que se move no sentido oposto ao fluxo tradicional da cadeia de suprimentos, ou seja, dos consumidores até os produtores. 
$\mathrm{Na}$ literatura nacional, poucos são os autores que buscam definir a logística reversa, tais como Shibao, Moori e Santos (2010) ao entenderem logística reversa como o planejamento dos custos relacionados ao fluxo de produtos, do seu ponto de consumo até o ponto de reprocessamento, com vistas a recuperar seu valor econômico. Outra visão é apresentada por Souza, Paula e Souza-Pinto (2012) que relacionam o termo logística reversa à reinserção de produtos inutilizados ao processo produtivo, como matéria-prima secundária, por meio das etapas de coleta e reprocessamento.

Destarte, como pôde ser visto, apesar de possuir diferentes definições, o termo logística reversa está sempre relacionado ao retorno de produtos descartados pela sociedade ao setor produtivo, para sua reinserção no ciclo de negócios ou destinação ambientalmente adequada. São três os principais fatores que motivam as organizações a tomarem a decisão de adotar a logística reversa, sendo estes (MILLER; SARDER, 2012).

- Governamentais, na forma de leis ambientais mais severas relacionadas a proteção do meio ambiente e a obrigação no recolhimento de produtos que perderam sua utilidade;

- Econômicos, por meio do uso da matéria-prima secundária originária de bens de pós-consumo que perderam sua utilidade, reduzindo os custos de produção de novos produtos;

- Ambiental, pois o recolhimento e uso de matéria-prima secundária reduz os danos causados pelo processo produtivo ao meio ambiente e gera uma imagem de empresa amiga do ambiente perante parceiros e clientes.

Entretanto, ao se tomar a decisão pela implantação da logística reversa, os gestores devem ter em mente que essa cadeia se estrutura como uma grande empresa formada por diferentes atores que realizam suas diversas etapas (ZUCATTO; WELLE; SILVA, 2013). Além disso, as tomadas de decisão inerentes a esse processo devem ser feitas levando em consideração benefícios para todos os envolvidos e não somente benefícios individuais para a empresa responsável pela adoção, gerenciamento e coordenação do processo (CHOPRA; MEINDL, 2010). 


\subsection{Tomada De Decisão}

Tomar decisões é algo intrínseco ao cotidiano da vida humana. Um jogador de futebol, por exemplo, tem que decidir de que lado vai bater a bola em uma cobrança de pênalti, uma dona de casa tem que decidir qual marca de sabão em pó comprar e um alto executivo tem que decidir que solução tomar para resolver um determinado problema em sua empresa.

Em geral, as pessoas tomam decisões de forma rápida, com o objetivo de solucionar um problema, com base em regras gerais denominadas heurísticas (BUENO; AZEVEDO, 2011) que simplificam a tomada de decisão a um simples julgamento (PLOUS, 1993), tendo como base a (TONETTO et al., 2006; YU, 2011):

- Ancoragem, quando o decisor utiliza algo como referência para tomar sua decisão, como, por exemplo, o preço de um computador em uma loja vai determinar o valor gasto na compra do produto;

- Disponibilidade, na qual a decisão se baseia em eventos ocorridos no passado, por exemplo, se uma pessoa tem que tomar a decisão entre viajar na estrada $A$ ou $B$, mas sabe que na $B$ ocorreu um grave acidente que o abalou, ela possivelmente irá escolher a estrada $A$;

- Representatividade, quando a decisão é tomada com base na ocorrência de um determinado fenômeno, por exemplo, uma pessoa tímida está indecisa entre ir ao cinema ou a boate, mas sabe que seus amigos também tímidos, na maioria dos casos, quando vão a boate não se divertem, então a probabilidade de não se divertir na boate é maior que no cinema, o que faz desse último a melhor opção em termos de lazer.

Contudo, nas organizações a tomada de decisão vai muito além de simples julgamentos baseados em heurísticas, sendo um processo complexo que deve ser completamente entendido por seus gestores e partes interessadas antes de ser adotado (NOORAIE, 2012). Ainda de acordo com os referidos autores, nas empresas, o processo de tomada de decisão é incremental, envolvendo fatores de eventos passados, circunstancias atuais e perspectivas, muitas vezes previstas por sistemas de Informação, do futuro.

Revista Produção Online, Florianópolis, SC, v.14, n. 2, p. 593-616, abr./jun. 2014. 
Corroborando Nooraire (2012), Cintra et al. (2013) afirmam que o processo decisório deve possuir elementos fundamentais como dados, informações e conhecimentos que permitam gerar um conhecimento do problema para que sejam levantadas propostas que busquem sua resolução e posterior aplicação da solução escolhida.

Contudo, a atual conjuntura competitiva do mercado globalizado exige das empresas tomadas de decisão cada vez mais rápidas, sem, no entanto, comprometer a qualidade do processo decisório e tampouco a qualidade dos resultados obtidos (VISENTINI; LÖBLER, 2013).

Para tanto, diversas organizações buscam diferentes maneiras de garantir maior eficiência e eficácia ao tomar decisões, podendo adotar sistemas informatizados de apoio a decisão, que fornecem projeções sobre eventos atuais e futuros, tanto internos, como externos à organização (LAUDON; LAUDON, 2011), ou utilizar modelos que auxiliem no processo decisório, tais como o modelo clássico de Simon (1977) que subdivide-se em quatro etapas: (1) inteligência, que corresponde à coleta de dados e análise do ambiente a fim de descobrir problemas ou oportunidades; (2) desenho, etapa na qual são levantadas e/ou criadas alternativas para solucionar o problema e a avaliação dos resultados; (3) escolha, etapa na qual uma das alternativas é escolhida e; (4) implementação, quando a alternativa escolhida é posta em ação, ou seja, quando a decisão é posta em prática.

Todavia, para Nooraie (2013), independente dos recursos que são utilizados para o processo de tomada de decisão, existem algumas características que devem ser levadas em consideração para reduzir as incertezas da escolha, tais características são divididas em:

Características específicas da decisão, tais como o impacto que a tomada de decisão pode gerar na empresa, sendo associado ao nível de risco que a decisão oferece, ou seja, se ela pode gerar ganhos reais ou grandes prejuízos se adotada e a complexidade da decisão, se ela é uma simples decisão gerencial e estruturada ou uma decisão complexa que envolva toda a empresa.

O ambiente interno da organização é outra característica que deve ser levada em consideração durante o processo decisório. Esse ambiente interno diz respeito ao tipo de estrutura, tamanho e performance da organização no mercado o qual está 
inserida. Agregado ao ambiente interno, fatores externos também devem ser analisados, tais como o dinamismo do ambiente e as oportunidades e riscos que ele pode oferecer.

Por fim, as características pessoais das pessoas que irão compor o grupo de gerentes/funcionários responsáveis pelo processo de tomada de decisão também deve ser visto, levando em conta a educação e experiência das pessoas no contexto no qual o problema está envolvido, o nível de consenso entre eles e até que ponto cada um desses gestores e funcionários estão propensos a apresentar soluções arriscadas.

Diante do exposto, fica claro que a tomada de decisão nas organizações é um processo complexo que envolve diferentes fatores na premissa de solucionar um problema ou obter vantagens competitivas por meio da geração de alternativas, na qual é escolhida a que reduza ao máximo as incertezas inerentes ao ambiente decisório.

\section{METODOLOGIA}

O presente estudo pode ser classificado como descritivo pois procura descrever algumas características da logística reversa relacionadas à inovação e tomada de decisão e, segundo Gil (2002), a pesquisa descritiva tem como principal objetivo descrever características de determinado fenômeno ou objeto.

Para realização da pesquisa foi feita uma análise bibliométrica. Para Araújo (2006), a análise bibliométrica permite ao pesquisador conhecer, através de dados coletados em documentos científicos, uma série de padrões relacionados ao campo estudado. Dessa forma, foram coletados artigos nas bases de dados de dois eventos de administração, escolhidos devido a sua abrangência e relevância perante a comunidade acadêmica: (1) Encontro da Associação Nacional de Pós-Graduação e Pesquisa em Administração (ENANPAD). Evento de abrangência Nacional, organizado pela Associação Nacional de Pós-graduação e Pesquisa em Administração (ANPAD), ocorrendo anualmente em diferentes cidades brasileiras, que em 2013 realiza sua 36a edição e; (2) Simpósio de Administração da Produção, Logística e Operações Internacionais (SIMPOI), Evento de abrangência Nacional, 
organizado pela Fundação Getúlio Vargas (FGV), ocorrendo anualmente, no qual o objetivo principal é a troca e compartilhamento de informações acadêmicas através da demonstração e divulgação de pesquisas. O evento em 2013 realiza sua $16^{a}$ edição.

Também foi incluído na pesquisa um evento de engenharia da produção, o Encontro Nacional de Engenharia da Produção (ENEGEP), escolhido devido a sua abrangência e relevância perante aos estudos relacionados à engenharia da produção. Outrossim, o fato da logística reversa compor a logística empresarial, retornando bens de pós-venda ou pós-consumo ao ciclo produtivo ou de negócios, também contribuiu para a escolha do evento.

O ENEGEP se caracteriza por ser um evento de abrangência nacional, organizado pela Associação Brasileira de Engenharia da Produção (ABEPRO), consolidando-se como um fórum para discussão de pesquisas relacionadas à engenharia da produção. O ENEGEP ocorre anualmente e em 2013 realiza sua 33ª edição.

Foram coletados 43 artigos, publicados entre os anos de 2007 e 2012, na base de dados digital disponível nos sítios de cada um dos eventos citados. Os artigos foram selecionados de acordo com os seguintes critérios: (a) possuir Logística Reversa como um dos termos do título; (b) ter realizado um estudo empírico do tipo estudo de caso e; (c) ter como tema central do estudo de caso o processo de logística reversa. A análise dos dados foi feita através do Software editor de planilhas Microsoft Excel 2010 e a discussão dos resultados são apresentados na seção a seguir.

\section{ANÁLISE DOS ARTIGOS E DISCUSSÃO DOS RESULTADOS}

A presente seção analisa os artigos coletados nas bases de dados dos eventos elencados na seção anterior, com três categorias de análise definidas a priori por meio da revisão da literatura sobre logística reversa, inovação em serviços e tomada de decisão, como forma de responder às questões definidas para esta pesquisa.

Revista Produção Online, Florianópolis, SC, v.14, n. 2, p. 593-616, abr./jun. 2014. 


\subsection{Revisão dos estudos de caso sobre logística reversa}

A pesquisa nas bases de dados utilizadas revelou uma desigualdade em relação à distribuição dos artigos sobre logística reversa durante os anos e nos eventos pesquisados.

Tabela 1 - Distribuição dos artigos de acordo com ano e evento

\begin{tabular}{|l|c|c|c|}
\hline & ENANPAD & SIMPOI & ENEGEP \\
\hline $\mathbf{2 0 0 7}$ & 0 & 1 & 4 \\
\hline $\mathbf{2 0 0 8}$ & 2 & 5 & 8 \\
\hline $\mathbf{2 0 0 9}$ & 0 & 2 & 0 \\
\hline $\mathbf{2 0 1 0}$ & 1 & 1 & 0 \\
\hline $\mathbf{2 0 1 1}$ & 3 & 0 & $\mathbf{7}$ \\
\hline $\mathbf{2 0 1 2}$ & 3 & 1 & $\mathbf{2 4}$ \\
\hline Total & $\mathbf{9}$ & $\mathbf{1 0}$ & 8 \\
\hline
\end{tabular}

Fonte: Autor (2013)

Como visto na tabela 1, o ENEGEP lidera a contagem de artigos publicados sobre estudos de caso envolvendo a logística reversa, contudo não houve mais crescimento de publicações após o ano de 2009. O ENANPAD e SIMPOI possuem poucas publicações sobre estudos empíricos acerca da logística reversa, não havendo também um crescimento de publicações ao longo dos anos.

Com relação aos setores estudados há uma distribuição mais equânime, diferente do que foi exposto na tabela 1, com destaque para o setor de eletrônicos com oito artigos (18,60\%), alimentício com sete artigos $(16,28 \%)$ e embalagens de agrotóxicos, com seis artigos (13,95\%).

Tabela 2 - Distribuição dos setores

\begin{tabular}{|c|c|c|}
\hline Setor & $\mathbf{N}^{\mathbf{0}}$ de artigos & $\%$ \\
\hline Eletrônicos & 8 & 18,60 \\
\hline Alimentício & 7 & 16,28 \\
\hline Embalagens de agrotóxicos & 6 & 13,95 \\
\hline Varejo & 2 & 4,65 \\
\hline Pneus & 4 & 9,30 \\
\hline Vasilhames de vidro & 3 & 6,97 \\
\hline Embalagens & 2 & 4,65 \\
\hline Briquetes & 1 & 2,32 \\
\hline Latas de bebidas & 2 & 4,65 \\
\hline Automotivo & 3 & 6,97 \\
\hline Garrafas pet & 1 & 2,32 \\
\hline Pilhas & 1 & 2,32 \\
\hline Instituição de ensino & 1 & 2,32 \\
\hline Produtos Lactéos & 1 & 2,32 \\
\hline Pneus e Eletrônicos & 1 & 2,32 \\
\hline TOTAL & $\mathbf{4 3}$ & $\mathbf{1 0 0}$ \\
\hline
\end{tabular}

Fonte: Autor (2013).

Revista Produção Online, Florianópolis, SC, v.14, n. 2, p. 593-616, abr./jun. 2014. 
Vale ressaltar que apenas três dos 43 artigos realizaram estudos de caso fora do Brasil, os outros 40 foram distribuídos de acordo com o que segue: Sudeste, 18 estudos (37,93\%); sul, seis estudos (20,68\%); nordeste, 8 estudos $(17,24 \%)$; norte, quatro estudos $(13,79 \%)$ e; centro-oeste, quatro estudos $(10,34 \%)$.

\subsection{Logística reversa como serviço inovador}

A análise dos estudos mostrou que dos 43 artigos somente em quatro a logística reversa não foi considerada uma inovação, pois três deles possuíam como unidade de análise a filial de uma grande empresa multinacional, como o Mcdonald's (MEI; CHRISTIANI; LEITE, 2011), a Tetra Park (PEREIRA; PAVANELLI; SOUZA, 2008), a Coca-cola (OLIVEIRA; SANTANA; SILVA, 2009), e uma fábrica de eletrodomésticos no Japão (GIOVINE; SACOMANO,2007), todas já adotantes da logística reversa.

Os demais estudos consideraram a logística reversa como uma inovação em serviço relacionada as suas práticas ambientais, haja visto que este processo era algo novo para as empresas que o implantaram.

Em relação à obtenção de vantagens competitivas oriundas desse processo inovador, parece haver uma unanimidade, já que $74,5 \%$ dos casos analisados afirmam que a logística reversa traz vantagens financeiras ou de imagem, como visto no estudo de Braga Junior, Merlo e Nagano (2008), na qual a adoção da logística reversa representou um aumento de 9,6\% em relação ao lucro líquido da empresa estudada, além de uma melhor imagem às organizações que a adotam, como no caso da logística reversa de garrafas pet, apresentado por Batista e Martins (2009), em que a adoção do processo contribuiu de forma positiva para a imagem corporativa e de seus clientes na organização estudada. Tais resultados empíricos confirmam o que foi visto na literatura, por meio de trabalhos como os de Silva, Pimenta e Campos (2013) e Miguez, Mendonça e Valle (2007), que a logística reversa pode trazer redução de custos e imagem diferenciada da empresa, ambos relacionados à obtenção de vantagem competitiva.

Sete dos 43 estudos analisados (16\%) afirmam que a adoção da logística reversa não trouxe vantagens competitivas e que sua adoção teve como objetivo 
minimizar o impacto ambiental, como ficou exposto no estudo realizado por Lopes, Tonini e Vieira (2007), no qual o principal motivo para a adoção da logística reversa foi dar a destinação adequada a embalagens vazias de agrotóxicos, diminuindo o risco de contaminação do meio ambiente. Assim como no estudo de Linhares, Cardoso e Oliveira Júnior (2008), na qual a adoção da logística reversa por uma instituição de ensino profissionalizante teve como objetivo minimizar os impactos ambientais causados pelos componentes químicos usados em seus laboratórios de ensino.

Entretanto, o objetivo de reduzir os impactos ambientais traz a tona a imagem de uma empresa preocupada com o ambiente para seus clientes, fazendo com que, mesmo indiretamente, tais empresas obtenham uma vantagem competitiva perante seus concorrentes, como "empresa ecologicamente correta".

\subsection{Tomada de decisão na adoção da logística reversa e em sua cadeia}

A tomada de decisão para a adoção da logística reversa teve como principal motivação solucionar problemas relacionados à leis e legislações ambientais em 29 $(67,44 \%)$ dos 43 casos analisados, corroborando com o que é visto na literatura sobre logística reversa, que cita que um dos fatores que levam as organizações a adotarem a logística reversa é a adequação às leis ambientais.

Os outros 14 estudos mostram que a decisão em adotar a logística reversa se deu por motivos como a redução de custos de produção e imagem diferenciada, como no caso estudado por Favero, Sant'Anna e Neto (2009), no qual a decisão de adotar a logística reversa se deu por conta dos altos custos financeiros e operacionais gerados pela devolução de produtos do pós-venda, e questões ambientais, como visto no trabalho de Souza e Lopes (2008), em que foi tomada a decisão de usar a logística reversa para embalagens de agrotóxicos como forma de reduzir a contaminação de ecossistemas, podendo assim comprometer a saúde humana.

Com relação ao processo decisório na rede de empresas que executam as etapas inerentes ao processo da logística reversa, a análise dos casos mostrou uma realidade diferente da apresentada por Yu (2011), que determina que o processo de

Revista Produção Online, Florianópolis, SC, v.14, n. 2, p. 593-616, abr./jun. 2014. 
tomada de decisão em uma organização em rede é feito de forma descentralizada, em que todos os participantes da rede participam do processo decisório.

Ficou constatado que somente dez (23,25\%) dos 43 estudos analisados possuíam um processo decisório descentralizado, na qual todos os membros da rede de empresas responsável pelo processo de logística reversa participavam, conforme afirmado por Yu (2011). Nos outros 33 estudos $(76,74 \%)$, o processo decisório era feito de forma exclusiva por uma única empresa, conforme pode ser visto no seguinte trecho do trabalho de Mendonça, Miguez e Valle (2009): "A escolha do tipo de logística reversa a ser adotado segue o modelo de tomada de decisão desenvolvido pela matriz da empresa”.

Dessa maneira, torna-se evidente que a decisão por adotar a logística reversa tem, na maioria dos casos, como objetivo solucionar problemas relacionados à leis e normas ambientais e que o processo decisório na rede de empresas responsável pela logística reversa, que de acordo com Pereira et al. (2012) envolve um alto número de problemas, tais como garantir a rentabilidade de todos os membros e definir as normas gerais de operação da rede é, na sua grande maioria, concentrado em uma única empresa, cabendo aos demais membros acatarem com as decisões tomadas.

\section{CONSIDERAÇÕES FINAIS}

A revisão de estudos sobre logística reversa realizada neste trabalho evidenciou a escassez, na literatura nacional, de trabalhos empíricos acerca do referido tema, algo já evidenciado pelo trabalho de Hernandez, Marins e Castro (2012), pois foram encontrados apenas 43 artigos que realizam estudos de caso sobre logística reversa em dois grandes eventos da área de administração e em um grande evento da área de engenharia da produção, área na qual a logística reversa está inserida.

A escassez de trabalhos sobre logística reversa no Brasil pode ter relação com a recente difusão do tema em âmbito nacional, que começou a ganhar proporções nos últimos 14 anos, após a obra de Paulo Roberto Leite, intitulada "Logística Reversa: Meio ambiente e competitividade", e a recente e crescente 
preocupação ambiental exposta na forma de leis, como a Política Nacional de Resíduos Sólidos, por exemplo.

Mesmo com a escassez de trabalhos empíricos, ficou evidente que a logística reversa pode trazer vantagens competitivas relacionadas à redução de custos de produção e imagem diferenciada perante a sociedade, pois somente sete dos 43 estudos analisados não apresentaram vantagens competitivas em relação a logística reversa.

Mesmo possuindo vantagens competitivas, a tomada de decisão para adoção da logística reversa teve por objetivo, na maior parte dos artigos analisados, solucionar problemas relacionados à leis e normas ambientais, fatores já evidenciados em estudos realizados por Nham, Souza e Aguiar (2003), Lopes (2004) e Gadia e Oliveira Júnior (2011).

Quando analisada como uma rede entre empresas, ficou constatado que o processo de tomada de decisão da logística reversa ocorre de forma centralizada, em que a tomada de decisão fica concentrada em uma única empresa, cabendo as demais acatar com as decisões tomadas. Isso vai de encontro com o que é visto na literatura, conforme afirma Yu (2011), que em organizações em rede o processo de tomada de decisão é descentralizado, no qual todas as empresas que compõem a rede participam.

O processo de tomada decisão centralizada em uma única empresa pode ocorrer pelo fato da logística reversa se estruturar, muitas vezes, como uma rede vertical, rede essa formada por um grupo de empresas na qual uma delas possui poder hierárquico diante das outras (MARCON; MOINET, 2000). Neste caso, a empresa que detém tal poder hierárquico é aquela que tomou a decisão em implantar a logística reversa como forma de solucionar problemas, como o cumprimento das leis e normas ambientais, formando parcerias ou criando outras empresas responsáveis pelas etapas ou parte das etapas inerentes à logística reversa.

A revisão dos estudos empíricos também deixou claro que a logística reversa era algo novo para a maioria das empresas que a adotaram, fazendo com que essa pudesse ser considerada uma inovação no modo como a cadeia de suprimentos é gerenciada e operada (VERMA; RAJAPORAL, 2013), já que a logística reversa 
trouxe as organizações adotantes um novo modelo de gestão para o descarte e reaproveitamento de bens de pós-consumo e pós-venda.

O presente trabalho limitou-se a realizar um levantamento de estudos empíricos acerca do tema logística reversa, contribuindo para evidenciar o atual estado da arte sobre este campo ainda pouco explorado. Isto posto, recomenda-se para a realização de novos trabalhos, o desenvolvimento de estudos empíricos que tenham por objetivo analisar, de forma mais profunda, como foi realizada a tomada de decisão em adotar a logística reversa em determinadas empresas, analisando também o processo decisório em cadeias de distribuição reversas já formadas. Também podem ser realizados estudos que visem compreender como a logística reversa, sob a ótica de uma inovação na cadeia de distribuição, muda a forma das organizações lidarem com a suas questões ambientais.

\section{REFERÊNCIAS}

ARAUJO, J. B.; ZILBER, S. N.; Adoção de e-business e mudanças no modelo de negócio: Inovação organizacional em pequenas empresas dos setores de comércio e serviços. Revista Gestão \& Produção, v. 20, n. 1, p. 147-161, 2013.

http://dx.doi.org/10.1590/S0104-530X2013000100011

ARAÚJO, C. A. Bibliometria: evolução histórica e questões atuais. Em Questão, v.12, n. 1, p. 11-32, jan./jun. 2006.

BARBIERI, J. C. Gestão ambiental empresarial: conceitos, modelos e instrumentos. 3. ed. São Paulo: Saraiva, 2011.

BARBOSA, A. J.; OLIVEIRA, O. V. Logística reversa: processo de reciclagem de resíduos nas associações do município de Fortaleza (CE). In: ENCONTRO DA ANPAD, 36., 2012, Rio de Janeiro. Anais... Rio de Janeiro, 2012.

BARRAS, R. Towards a theory of innovation in services. Research Policy, v. 15, n. 4, p. 161-173, 1986. http://dx.doi.org/10.1016/0048-7333(86)90012-0

BATISTA, M. V. F.; MARTINS, E. F. Identificação e avaliação dos canais logísticos reversos: Um estudo sobre a revalorização de garrafas pet. In: ENCONTRO NACIONAL DE ENGENHARIA DE PRODUÇÃO, 29., 2009, Salvador. Anais... Salvador, 2009.

BRAGA JUNIOR, S. S. B.; MERLO, E. M.; NAGANO, M. S. Um estudo comparativo das práticas de logística reversa no varejo de médio porte. In: SIMPÓSIO DE 
ADMINISTRAÇÃO DA PRODUÇÃO, LOGÍSTICA E OPERAÇÕES

INTERNACIONAIS, 11., 2008, São Paulo. Anais... São Paulo, 2008.

BUENO, L. R. P.; AZEVEDO, M. C. Produção científica na tomada de decisão organizacional estratégica. In: ENCONTRO NACIONAL DA ANPAD, 35., 2011, Rio de Janeiro. Anais... Rio de Janeiro, 2011.

CAMPOS, L. M. S.; MELO, D. A. Indicadores de desempenho dos Sistemas de Gestão Ambiental (SGA): uma pesquisa teórica. Produção. v. 18, n. 3, p. 540-555, 2008. http://dx.doi.org/10.1590/S0103-65132008000300010

CHAN, F. T. S.; ZHANG, T. The impact of Collaborative Transportation Management on supply chain performance: a simulation approach. Expert Systems with Applications, v. 38, n. 3, p. 2319-2329, 2011. http://dx.doi.org/10.1016/j.eswa.2010.08.020

CHOPRA, S; MEINDL, P. Supply chain management: strategy, planning and operation. 4. ed. New Jersey: Pearson Education, 2010.

Cintra, R. F. et al. A informação do setor de faturamento como suporte à tomada de decisão: um estudo de caso no Hospital Universitário da UFGD. Ciência \& Saúde Coletiva, v. 18, n. 10, p. 3043-3053, 2013.

http://dx.doi.org/10.1590/S1413-81232013001000029

COMISSÃO MUNDIAL SOBRE MEIO AMBIENTE E DESENVOLVIMENTO (CMMAD). Nosso Futuro Comum. Rio de Janeiro: FGV, 1988.

DAVENPORT, T. H. Process innovation: reengineering work through information technology. Cambridge: Harvard Business School Press, 1992.

FARIA, A. C.; PEREIRA, R. S. O processo de logística reversa de embalagens de agrotóxicos: um estudo de caso sobre o INPEV. Organizações rurais e Agroindustriais, v. 14, n. 1, p. 127-141, 2012.

FAVERO, D.; SANT'ANNA, C. H. M.; NETO, J. S. C. Impactos e resultados do gerenciamento da logística reversa numa central de distribuição de alimentos: um estudo de caso. In: ENCONTRO NACIONAL DE ENGENHARIA DE PRODUÇÃO, 29., 2009, Salvador. Anais... Salvador, 2009.

Ferreira Filho, H. R.et al. Logística reversa: um estudo de caso em uma empresa pública de briquetes no município de Tailândia - Pará. In: ENCONTRO NACIONAL DA ANPAD, 35., 2011, Rio de Janeiro. Anais... Rio de Janeiro, 2011.

FIATES, G. G. S.; FIATES, J. E. A. A informação como estratégia em ambientes turbulentos. In: Estratégias: formulação, implementação e avaliação: o desafio das organizações contemporâneas. São Paulo: Saraiva, 2008. 
Flygansvaer, B. M., Gadde, L-E., Haugland, S. A. Coordinated action in reverse distribution systems. International Journal of Physical Distribution \& Logistics Management, v. 38 n. 1, p. 5-20, 2008. http://dx.doi.org/10.1108/09600030810857184

GADIA, G. C. M. L.; OLIVEIRA JÚNIOR, M. A. A logística reversa como instrumento de ação na garantia da sustentabilidade ambiental: análise das inovações trazidas pela política nacional de resíduos sólidos. Revista IDEA, v. 2, n. 2, 2011.

GIL, A. C. Como elaborar projetos de pesquisa. 4. ed. São Paulo: Atlas, 2002. 175 p.

GIOVINE, H.; SACOMANO, J. B. A logística reversa como instrumento de melhoria do meio ambiente: Um estudo de caso sobre a fábrica de reciclagem de eletrodomésticos da matsushita. In: ENCONTRO NACIONAL DE ENGENHARIA DE PRODUÇÃO, 27., 2007, Foz do Iguaçu. Anais... Foz do Iguaçu, 2007.

GONÇALVES-DIAS, S. L. F.; TEODÓSIO, A. S. S. Perspectivas de análise do ambientalismo empresarial para além de demonizações e santificações. Revista de Gestão Social e Ambiental, v. 5, n. 2, p. 03-17, 2011.

HERNANDEZ, C. T.; MARINS, F. A. S.; CASTRO, R. C. Modelo de Gerenciamento da Logística Reversa. Gestão e Produção, v. 19, n. 3, p. 445-456, 2012. http://dx.doi.org/10.1590/S0104-530X2012000300001

LAGARINHOS, C. A. F.; TENÓRIO, J. A. S. Logística reversa dos pneus usados no Brasil. Polímeros, v. 23, n. 1, p. 49-58, 2013.

LAUDON, K.; LAUDON, J. Sistemas de informação gerenciais. 9. Ed. São Paulo: Pearson, 2011.

LEITE, P. R. Logística reversa: meio ambiente e competividade. 2. ed. São Paulo: Prentice Hall, 2009.

LEITE, P. R. Direcionadores estratégicos em programas de logística reversa no Brasil. Revista Alcance, v. 19, n. 2, p. 182-201, 2012.

LINHARES, A. C. S.; CARDOSO, P. A.; JUNIOR, O. C. Logística reversa: o caso do destino de produtos químicos e vidrarias de uma instituição de ensino profissionalizante em Curitiba. In: Encontro Nacional de Engenharia de Produção, 28., 2008, Rio de Janeiro. Anais... Rio de Janeiro, 2008.

LOPES, J. R. M. Sistema de gestão ambiental integrada - SGAI: uma análise econômica estrutural. In: CONGRESSO ACADÊMICO SOBRE O MEIO AMBIENTE E DESENVOLVIMENTO SUSTENTÁVEL DO RIO DE JANEIRO, 1., 2004, Rio de Janeiro. Anais... Rio de Janeiro, 2004. 
LOPES, A. C. V.; TONINI, M. C. S. M.; VIEIRA, S. F. A. Logística reversa um estudo das embalagens vazias de agrotóxico. In: Encontro Nacional de Engenharia de Produção, 27., 2007, Foz do Iguaçu. Anais... Foz do Iguaçu, 2007.

LOUNSBURY, M.; CRUMLEY, E. T. New practice creation: an institutional perspective on innovation. Organizational Studies, v. 28, n. 7, pp. 993-1012. 2007.

MACAGNO, T. A Model for Managing Corporate Sustainability. Business and Society Review, v. 118, v. 2, p. 223-252, 2013.

MARCON, C.; MONET, N. La Stratégie-Réseau.Paris: Éditions Zéro Heure, 2000.

MCMURRAY, A. J. et al. Workplace innovation in a nonprofit organization. Nonprofit management \& leadership, v. 23, n. 3, 2013. http://dx.doi.org/10.1002/nml.21066

MEI, L. B.; CHRISTIANI, V. S.; LEITE, P. R. A logística reversa no retorno de óleo de cozinha usado. In : ENCONTRO NACIONAL DA ANPAD, 35., 2011, Rio de Janeiro. Anais... Rio de Janeiro, 2011.

MENDONÇA, F. M.; MIGUEZ, E. C.; VALLE, R. A. B. Os benefícios ambientais e econômico-financeiros de políticas de logística reversa de produtos eletrônicos no Brasil. In: Encontro Nacional de Engenharia de Produção, 29., 2009, Foz do Iguaçu. Anais... Foz do Iguaçu, 2009.

MIGUEZ, E. C.; MENDONÇA, F. M.; VALLE, R. Impactos Ambientais, sociais e financeiros de uma política de logística reversa adotada por uma fábrica de televisão - um estudo de caso. Produção Online, Edição Especial, 2007.

http://dx.doi.org/10.14488/1676-1901.v7i4.54

MILLER, C. R.; SARDER, M. D. Public Works Policy Implications of Sustainable Reverse Logistics Operations. Public Works Management \& Policy, v. 17, n. 1, p. 68-82, 2012. http://dx.doi.org/10.1177/1087724X11429044

MOREIRA, M. F.; VARGAS, E. R. Compras para a inovação: casos de inovações induzidas por clientes públicos. Revista de Administração Mackenzie, v. 13, n. 5, p. 232-257, 2012. http://dx.doi.org/10.1590/S1678-69712012000500009

MUNASINGHE, M. Sustainable development triangule. 2007. Disponível em: <http://www.eoearth.org/article/Sustainable_development_triangle>. Acesso em: 10 set. 2012.

NHAM, A. N. P.; SOUZA, C. G.; AGUIAR, R. A. A. Logística reversa no Brasil: a visão dos especialistas. In: ENCONTRO NACIONAL DE ENGENHARIA DE PRODUÇÃO, 23., 2003, Ouro Preto. Anais... Ouro Preto, 2003.

NOORAIE, M. Factors influencing strategic decision-making processes. International Journal of Academic Research in Business and Social Sciences, v. 2, n. 7, 2012.

Revista Produção Online, Florianópolis, SC, v.14, n. 2, p. 593-616, abr./jun. 2014. 
OLIVEIRA, A. D.; SANTANA, E. M.; SILVA, S. C. Logística reversa das embalagens retornáveis: Uma alternativa para a redução de custos para o desenvolvimento sustentável. In: ENCONTRO NACIONAL DE ENGENHARIA DE PRODUÇÃO, 29., 2009, Salvador. Anais... Salvador, 2009.

Pereira, A. L.et al. Logística reversa e sustentabilidade. São Paulo: Cengage Learning, 2012.

Plous, S. The psychology of judgment and decision making. USA: McGraw-Hill, 1993.

POCHAMPALLY, K. K.; NUKALA, S. \& GUPTA, S. M. Strategic planning models for reverse and closed-loop supply chains. Boca Raton: CRC Press, 2009.

PORTUGAL, N. S. Contribuições da logística reversa ao método de valoração ambiental dos custos evitados: um estudo de caso em uma Indústria de Autopeças. In: ENCONTRO DA ANPAD, 36., 2012, Rio de Janeiro. Anais... Rio de Janeiro, 2012.

PRZYCHODZEN, J.; PRZYCHODZEN, W. Corporate sustainability and shareholder wealth. Journal of Environmental Planning and Management, v. 56, n. 4, p. 474493, 2013. http://dx.doi.org/10.1080/09640568.2012.685927

RESENDE JUNIOR, P. C.; GUIMARÃES, T. A. Inovação em serviços: o estado da arte e uma proposta de agenda de pesquisa. Revista Brasileira de Gestão de Negócios, v. 14, n. 44, p. 293-313, 2012.

ROGERS, E. M. Diffusion of innovation. New York, NY: Free Press, 1962.

ROGERS, D. S.; Tibben-Lembke, R. S. An examination on reverse logistics practices. Journal of Business Logistics. v. 22, n. 2, p.129-148, 2001. http://dx.doi.org/10.1002/j.2158-1592.2001.tb00007.x

RUBIO, S.; CHAMORRO, A.; MIRANDA, F. J. Characteristics of the research on reverse logistics (1995-2005). International Journal of Production Research, v. 46, n. 4, p. 1099-1120, 2008. http://dx.doi.org/10.1080/00207540600943977

SELLITTO, M. A. ET AL. Gestão de cadeias de suprimentos verdes: quadro de trabalho. Produção Online, v. 13, n. 1, p. 351-374, 2013.

http://dx.doi.org/10.14488/1676-1901.v13i1.1181

SELLITTO, M. A. ET AL. Coprocessamento de cascas de arroz e pneus inservíveis e logística reversa na fabricação de cimento. Ambiente \& Sociedade, v. 16, n. 1, p. 141-162, 2013. http://dx.doi.org/10.1590/S1414-753X2013000100009

SCHUMPETER, J. A. Business cycles: A theoretical, historical, and statistical analysis of the capitalist process. New York, London: McGraw-Hill, 1939. 
SHEU, J.; TALLEY, W. Green supply chain management: trends, challenges, and solutions. Transportation Research Part E, v.47, n.6, p.791-792, 2011.

http://dx.doi.org/10.1016/j.tre.2011.05.014

SHIBAO, F.; MOORI, R.; SANTOS, M. R. A Logística reversa e a sustentabilidade Empresarial. In: SEMINÁRIOS EM ADMINISTRAÇÃO, 13., 2010, São Paulo.

Anais... São Paulo, 2010.

SILVA, L. A. A. Logística Reversa dos resíduos eletrônicos do setor de informática: Realidade, Perspectivas e Desafios na cidade do Natal-RN. Produção Online, v. 13, n. 2, p. 544-576, 2013. http://dx.doi.org/10.14488/1676-1901.v13i2.1133

SIMON, H. A. New Science of management decisions. New York: Prentice-hall. 1977.

SMITH, R. The evolution of innovation. Research Technology Management, v. 51, n. 3, p. 51-55, 2008.

SOUZA, A. G.; LOPES, A. C. V. Contribuição da logística reversa de embalagens agrotóxicas para a preservação do meio ambiente um estudo de caso da aregran. In: ENCONTRO NACIONAL DE ENGENHARIA DE PRODUÇÃO, 28., 2008, Rio de Janeiro. Anais... Rio de Janeiro, 2008.

SOUZA, PAULA, SOUZA-PINTO. O papel das cooperativas de reciclagem nos canais reversos de pós-consumo. Revista de Administração de Empresas, v. 52, n. 2, p. 246-262, 2012. http://dx.doi.org/10.1590/S0034-75902012000200010

Tonetto, L. M.et al. O papel das heurísticas no julgamento e na tomada de decisão sob incerteza. Estudos de psicologia. v. 23, n. 2, pp 181-189, 2006.

http://dx.doi.org/10.1590/S0103-166X2006000200008

VERMA, R.; RAJAGOPAL. Conceptualizing Service Innovation Architecture: a service-strategic framework. Journal of Transnational Management, v. 18, p. 3-22, 2013. http://dx.doi.org/10.1080/15475778.2013.751869

VISENTINI, M. S.; LÖBLER, M. L. Atenuantes do efeito do compartilhamento da informação na decisão grupal: foco na familiaridade e na discordância entre os decisores. Revista de Administração, v. 48, n. 3, p. 409-425, 2013.

http://dx.doi.org/10.5700/rausp1096

WHITE, M. A. Sustainability: I know it when I see it. Ecological Economics, v. 86, p. 213-217, 2013. http://dx.doi.org/10.1016/j.ecolecon.2012.12.020

WU, J.; MA, L.; YANG, Y. Innovation in the chinese public sector: typology and distribution. Public Administration, v. 91, n. 2, 2013.

http://dx.doi.org/10.1111/j.1467-9299.2011.02010.x

Revista Produção Online, Florianópolis, SC, v.14, n. 2, p. 593-616, abr./jun. 2014. 
YU, A. S. O. Tomada de decisão nas organizações. São Paulo: Saraiva. 2011.

ZUCATTO, L. C.; WELLE, I.; SILVA, T. N. Cadeia reversa do óleo de cozinha: coordenação, estrutura e aspectos relacionais. Revista de Administração de Empresas, v. 53, n.5, p. 442-453, 2013.

http://dx.doi.org/10.1590/S0034-75902013000500003

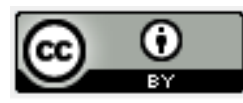

Artigo recebido em 02/09/2012 e aceito para publicação em 23/04/2014

DOI: http://dx.doi.org/10.14488/1676-1901.v14i2.1434

Revista Produção Online, Florianópolis, SC, v.14, n. 2, p. 593-616, abr./jun. 2014. 